\title{
Power Industry Trusted Software Technology: A Case Study of Poland
}

\author{
Jozef B. Lewoc ${ }^{1,}$ Slawomir Skowronski1 ${ }^{2,}$ Marion A. Hersh ${ }^{3,}$ Larry \\ Stapleton $^{4,}$ Vesna Ojleska ${ }^{5,}$ Antoni Izworski ${ }^{6,}$ Antonina Kieleczawa ${ }^{7}$ Peter \\ Kopacek $^{8,}$ Georgi Marko Dimirovski ${ }^{9}$ \\ ${ }^{l}$ Design, Research and Translation Agency Leader Wroclaw, Poland \\ ${ }^{2}$ Informatics and Management Faculty Wroclaw University of Technology Wroclaw, Poland \\ ${ }^{3}$ Electronic and Electric Engineering Department, University of Glasgow, Glasgow, Scotland \\ ${ }^{4}$ ISOL Research Centre, Waterford Institute of Technology, Waterford, Republic of Ireland \\ ${ }^{5}$ Cyril and Methodius University of Skopje Skopje, Macedonia \\ ${ }^{6}$ Institute of Automation and Robotics Wroclaw University of Technology Wroclaw, Poland \\ ${ }^{7}$ Institute for Power System Automation (IASE)Wroclaw, Poland \\ ${ }^{8}$ Institute for Handling Devices and Robotics Vienna University of Technology Vienna, Austria \\ ${ }^{9}$ Computer Engineering Dogus University Istanbul, Turkey
}

\begin{abstract}
The present pa per discusses the problems of trusted software (including specialized operating systems) for the technology change and transfer in the domain of pioneering (emerging then) automation and ICT systems for the power industry in a rather not much developed case study country (Poland) and their basic solutions. The costs that had to be paid by the leading designers of large-scale projects are also mentioned, since they are, sometimes, more important than the actual technical and/or research solutions of the trusted software issues.
\end{abstract}

Keywords: Power industry, automation, information and communication technology, emerging applications, trusted software/hardware, design, costs.

\section{INTRODUCTION}

The problems of trusted software and hardware systems for the in the technology change and transfer process in rather poorly developed countries being the technology recipients is rather interesting. It was undertaken in $[1,2]$ in the case studies of Poland. The case study country seems to be rather well selected for the pioneering period of automation and ICT since the domains were developed better there than in other similar ones, at a similar development level.

The power industry, where trusted systems are needed very severely due to possible high costs of system errors or the control engineers' mistakes. The situation was very difficult due to unreasonable embargos at the pioneering time: the Red Army had never any problems with providing their missiles or fighters but the design and development team (the Team) could not by a good computer for this civilian application domain. This resulted in that the trusted systems must have been built using hardware obsolete od some $5-10$ years with regard to that available in well developed countries and they were successful.

The first successful case study application of ICT in the power industry automation in the case study country is discussed below. 


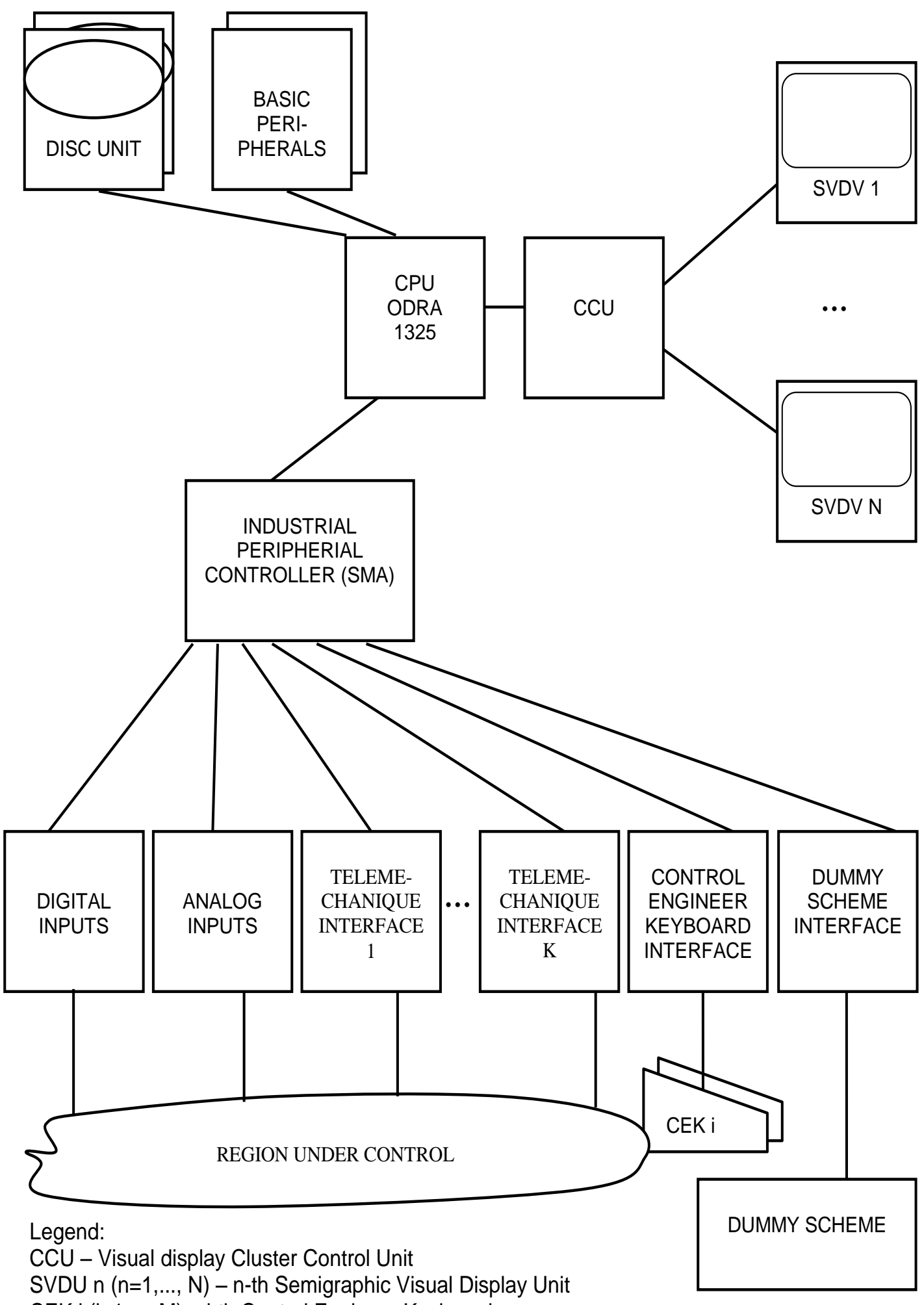
CEK i $(i=1, \ldots, M)$ - i-th Control Engineer Keyboard

Fig. 1. SAPI ODM hardware architecture 


\section{REGIONAL POWER SYSTEM CONTROL CENTRES (SAPI ODM)}

\section{A. General Information}

The regional power system control centres were planned to aid the power system control engineers/dispatchers, first of all for the regional power system hierarchy level. The data was entered from the power system region under control via analogue and digital inputs as well as power-industry-oriented telemechanique interfaces $1, \ldots, \mathrm{K}$. The data was processed in the Central Processing Unit (CPU), dis[played on the tabular visual displays (SVDU1-N) and printers (basic peripherals), and archived on the discs. Other inputs/outputs are provided for the control engineers were provided via ther standard and specialised (power industry oriented) keyboards and dummy schemes.

The Odra 1325 computer [3] was based on the ICL 1902a Central Processing Unit (CPU) intended for numerical data processing only and was developed in the discrete germanium component technology, which was the must for the Team working in the case study country. In addition, it was found, during the laboratory tests, the CPU was tripped up to several times a day due to poorly designed operating amplifiers of the internal memory. And SAPI ODM was to be, of course, a successful trusted system. Therefore, it was decided to develop a special-purpose power-industry oriented software system of the general architecture presented in Fig. 2

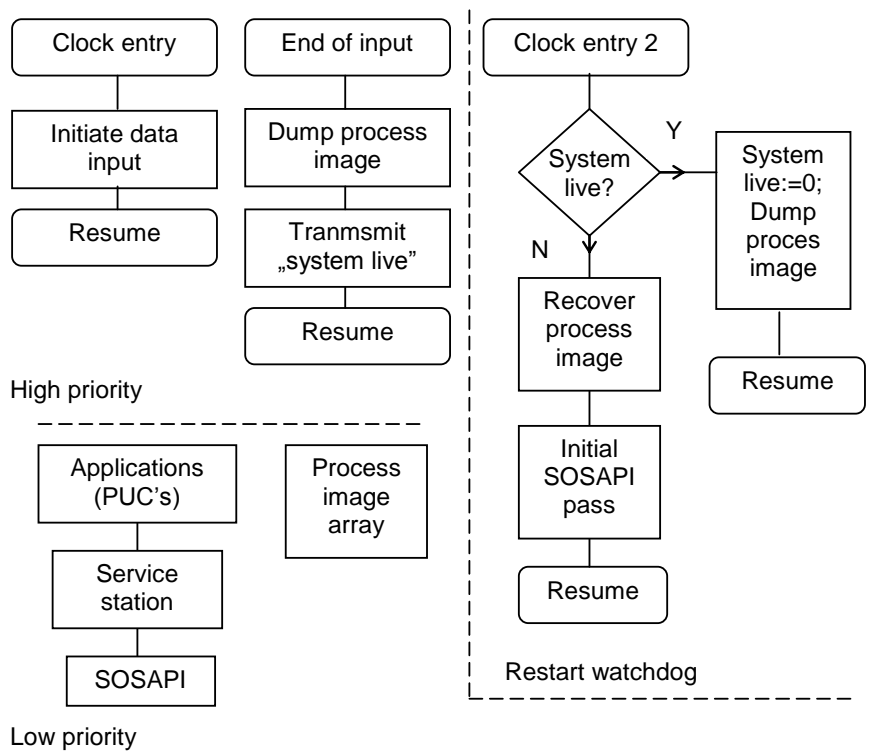

Fig. 2 Software architecture of SAPI ODM

The development of the home-made operating system SPSAPI (from Polish System Operacyjny Sustemu Automatycznego Przetwarzania Informacji = Operating System of Automatic Data Processing) was decided upon in order to release the power-industry application programmers from the need of programming various power-industry-oriented peripherals, including, among other coordination of the software system and to provide the trustworthy SAPI ODM system, without the necessity of bothering the application programmers with the specific computer-oriented programming and diagnostic problems.

\section{B. Software System of SAPI ODM}

\section{a) General problems}

The first design issue related with the SAPI ODM trustiness was that all the process data were maintained in a Process image array of SOSAPI, available to the Programs Under Control (PUCs) via the operating system only. This made it possible that two applications could not destroy (at least formally, i.e. within the primary programming processing steps). It was of a special significance for analogue data where a CPU word of 24 bits included the actual and current mean value plus some control data. It was avoided that applications could change individual bits or bytes of the Process image that could lead to unforeseeable errors in the process data. 
This enabled to develop another desirable feature of SAPI ODM: an ability of a quick restart: the system was capable of being restarted within a fraction of a second, after the system restart/recovery from the last successful disk dump was initiated was initiated.

The primary processing of the process data (and the SVDU data) was programmed by the Leading Designer of SAPI ODM (the Leader) of the widest experience in ICT applications in automation in the case study country (actually available from only the two ICT automation systems, the designer of the first case study country computer automation system [2]). This was also a meaningful step towards the trusted SAPI ODM.

Another reasonable step in this direction were the performance evaluation studies for ICT automation system/network performance evaluation [4]. Due to the performance evaluation experience and intuition described in [4], SAPI ODM performance aspects could be predicted and verified with the conclusion necessary for the system trustworthiness: all data acquisition and processing tasks of SAPI ODM are feasible under SAPI ODM, even if the initial number of the analogue variables (roughly a thousand) and of the digital variables (roughly a dozen thousands) are increased even by an order of magnitude. Note that, the computing power of the CPU was more than 5 or even 10 times lower than those of the popular control minicomputers available at that time in well developed countries.

(B. Specific problems

The "non repairable" design defect of CPU seemed to be the strong enough reason for disqualifying Odra 1325 as a central processor of any ICT automation system/network due to that it did not make it possible to develop trusted systems. In fact, in late seventies, many automation systems projects based on application of Odra 1325 + SMA failed because of missed trustiness. However, in the power industry, systems were much bigger (Ref. the paragraph above) than in other industries and several people tried to solve this problem.

The Gdańsk Colleagues of the Team thought in such way: what can the control engineer do after a CPU trip: to reset the power supply of the CPU and to restart SAPI ODM. Normally, it would take a few up several dozen minutes, it would be annoying for the power system control engineers (dispatchers) who would, probably, resign of the system. But the actions of the dispatcher can be automatized and they could be performed within a fraction of a second and, in practice, would be invisible for the control engineers (except for possible logs for diagnostic purposes).

The Gdańsk idea implemented in SAPI ODM worked perfectly: The first implementation in the system in the Central Power Industry Region of the case study Country was a remarkable success, especially when several months after SAPI ODM commissioning in the Region, the system made it possible to save a 130 MW power generating unit in the Siekierki Heat and Power Generating Plant (the biggest one in Europe, the second biggest in the world). The costs of the phenomenon of the rotor to "go out through the roof" would amount to USD several million; this single event paid back all outlays for ICT in the cases study Country, till that moment. The power industry recognized the SAPI ODM as a trustworthy system which was usefully operated in several locations for close to twenty years. In other power system distribution boards where the local IT people did not believe in the success of SAPI ODM and used Odra 1325 intended for SAPI ODM as a store of replacement processor PC boards, started to give the taken PC boards fast and their SAPI ODMs were successfully commissioned soon.

To summarise, though the systems were based on the Odra 1325 computer, ICL 1902a compatible, intended for scientific and low-scale business data processing, their trustworthiness values were upgraded by the Team of the Leader in a high degree and they monitored effectively more than $50 \%$ power flowing in the power grid in the case study country for almost 20 years. Though the CPU tripped off even several times a day, the automatic restart devised and implemented provided for the availability factor exceeding $92 \%$ (pre-planned repair time included in the unavailability period), what was, at the time of implementation a measure of trustworthiness provided by the world top ICT control system/networks suppliers. The economic benefits produced by SAPI ODMs and calculated by official algorithms exceeded US billion 40 !

The software of SAPI ODM was a process control oriented operating system SOSAPI and a collection of application program under control (PUC). A task of a vital importance for SAPI ODM was the SAPI ODM clock-driven restart/recovery task detecting CPU failures/trips and reinitiating automatically operation of the system. Due to the easy and fast operation restart feature of SOSAPI ODM and the application software, a simple electronic restart watchdog as well as software performing the actions depicted in Fig. 2. The solution worked correctly though it were the first large scale applications in the power system of the case study country [5.6,7].

And all this was possible because, at a very high degree, of the due consideration of the trusted system/network,. operating system and application aspects . 


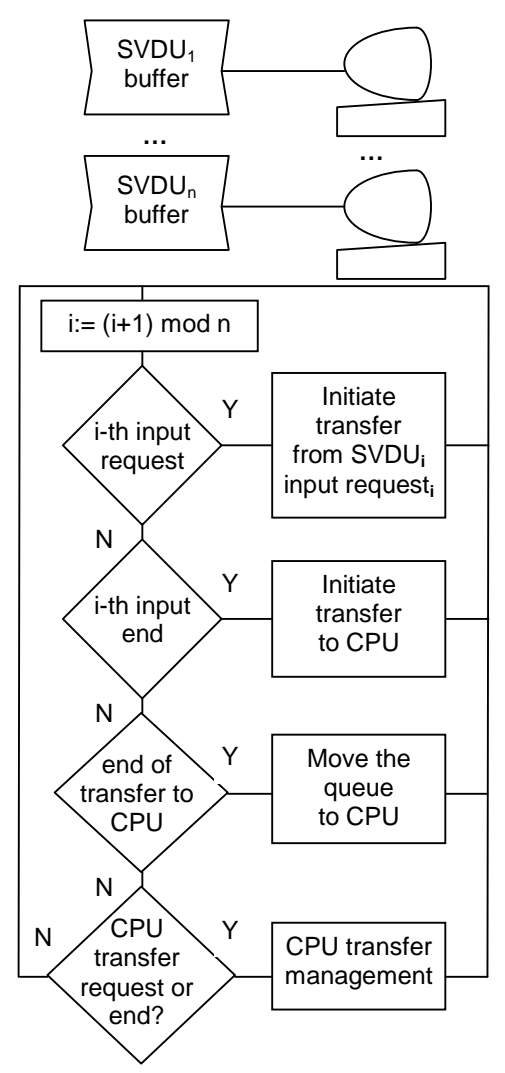

Fig. 3 Functional architecture of intelligent power system visual display unit cluster (VDUC)

\section{b) SVDU Smart Cluster Control Unit}

Though the semi-graphic visual displays delivered by ICL were technically very good, their price was a barrier for SAPI ODM applications at the lower hierarchy level. Therefore, the first Polish twocomputer system was developed and the software enabling inter-computer operation and servicing of home and/or imported semi-graphic and/or tabular VDUs operating in the remote serial data transmission mode was launched.

The trustworthiness aspects include here the fast transmission recovery features, professional programming approach and standard self-restart VDUC features providing the trustworthy capabilities. No specific automatic restart watchdog hardware/software was required; within the general restart action, CPU Odra 1325 initiated also the peripheral device restart.

The solution presented here was successfully applied in several SAPI-ODM-derivative power industry ICT applications described below [8].

\section{c) Power Generating Unit Monitor}

The power generating unit monitor (PGUM) was a test version of SAPI ODM adapted for monitoring of big power generating units (PGU), realized within the scope of the ICT systems and networks intended for the planned Nuclear power generating station in the case study country.. The test version was implemented for a 200 MW PGU and passed the planned operational tests and trials [6]. 


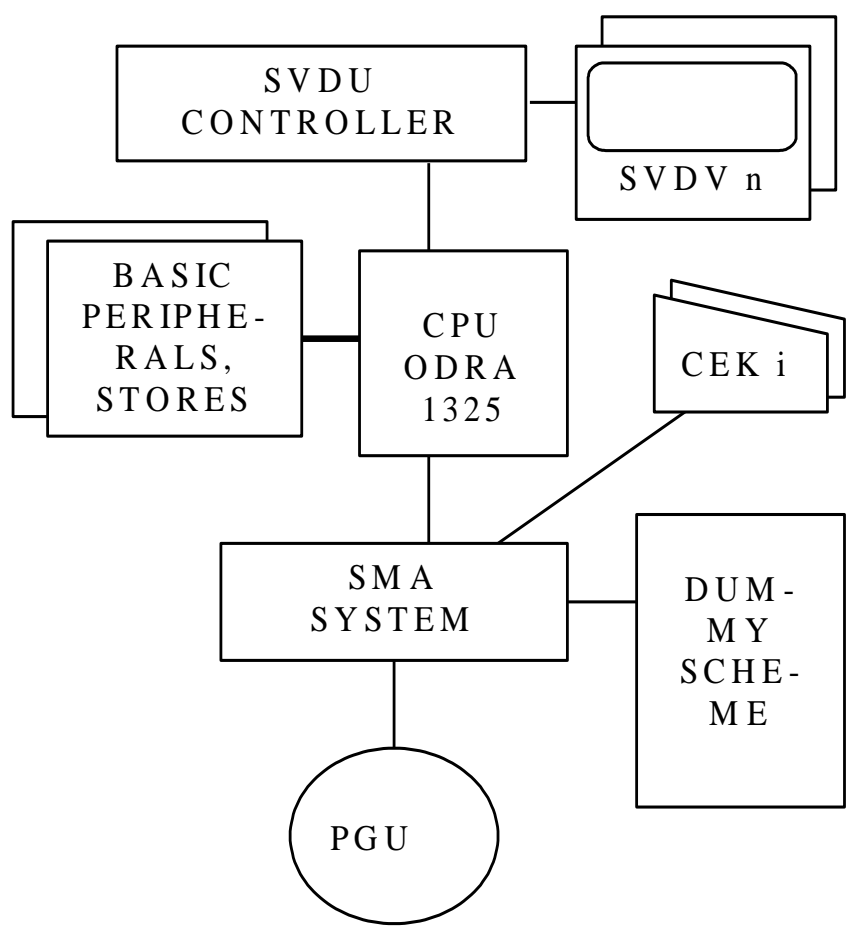

Fig. 4 Basic hardware architecture of PGUM

All the trusted-software solutions described hereinabove for SAPI ODM were applied in PGUM and proved satisfactory for this test application of trusted systems.

\section{d) Power Network Simulator}

To prepare the training power network simulator, a major modification of the operating system SOSAPI was done. A new class of PUCs was introduced, realizing urgent simulation coordination tasks. A set of application-specific PUCs was written. It should be emphasized that the computers enabling full network simulation in real-time become available even in the well developed countries some dozen or so years later. The problem was solved so that experience trainers prepared network responses for various events and the simulator used them in accordance with the network conditions and changes. Here, the high trustiness was ensured due to the high Leading Trainer's experience as a power grid control engineer/dispatcher [9].

The trustworthiness-oriented solutions of SOSAPI ODM proved to be adequate for this case of two preemptive resume Program Under Control priority classes.. Due to that, the simulator was operated successfully for some dozen years and almost each power network control engineer in the case study country passed training in operation of the electric power grid during that time period. 


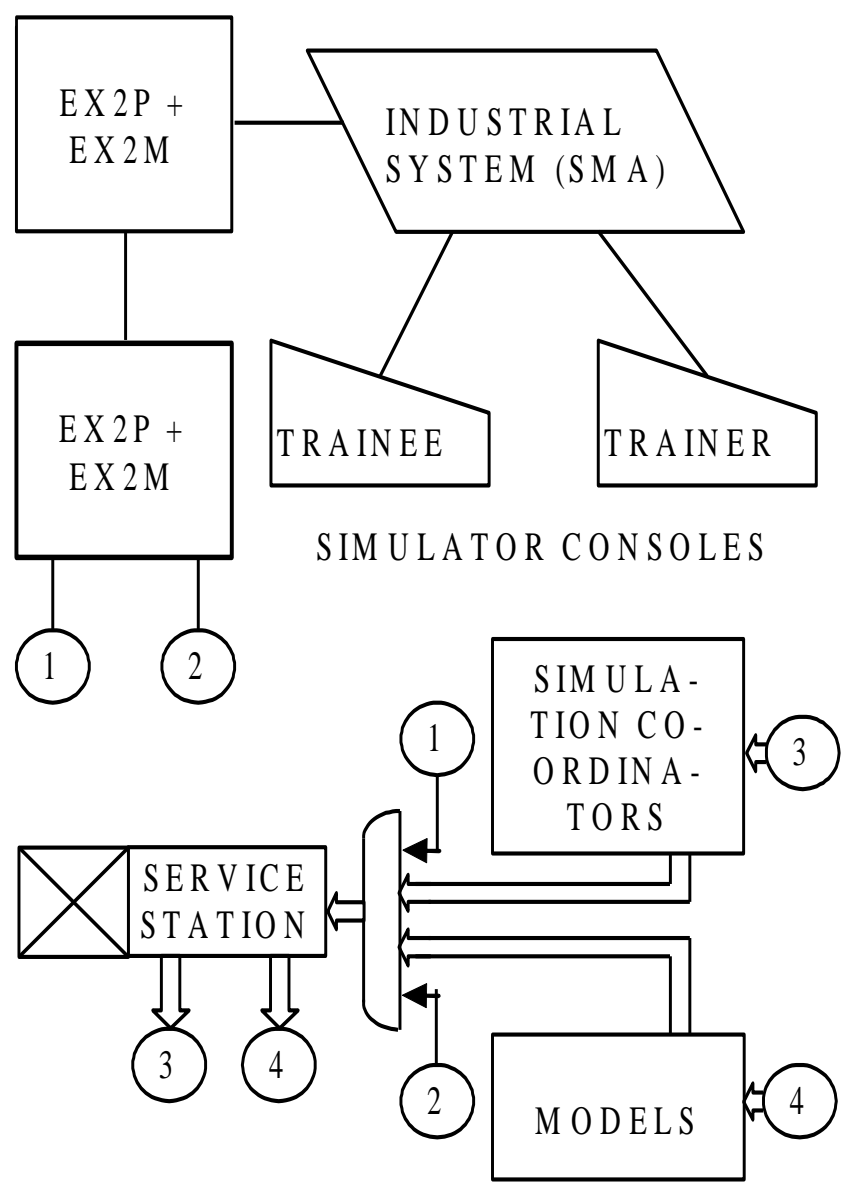

Fig. 5. Functional architecture of the simulator

e) KWP-Microprocessor-based version of SAPI ODM

When the microprocessor technology became available in the case study country, it became possible to transfer the solutions developed for SAPI ODM into small devices called KWP (commutated measurement display) and use them in smaller power industry utilities. KWP was a successful solution and the severe economy down period was the basic reason for limited proliferation of the device [10].

KWP was developed by transferring a subset of all basic SAPI ODM functionalities, including those devoted to trustiness. Additionally, is was an auto-starting unit, continuously operating trusted among the power industry organizational units where it was implemented.

\section{f) System 10, Power Plant Data Base Badel}

This novel project intended to enable computer integration of manufacturing and management domains in power plants was initiated for a big thermal power plant under development but was delayed for several due to the down economy period and, consequently, low demand for electric power in the case study country. Nevertheless, the solutions developed on this project have been successfully applied in more than two hundred power plants and heat and power generating plants, even in the present time of a severe competition in the power industry. 
Power Industry Trusted Software Technology: A Case Study of Poland

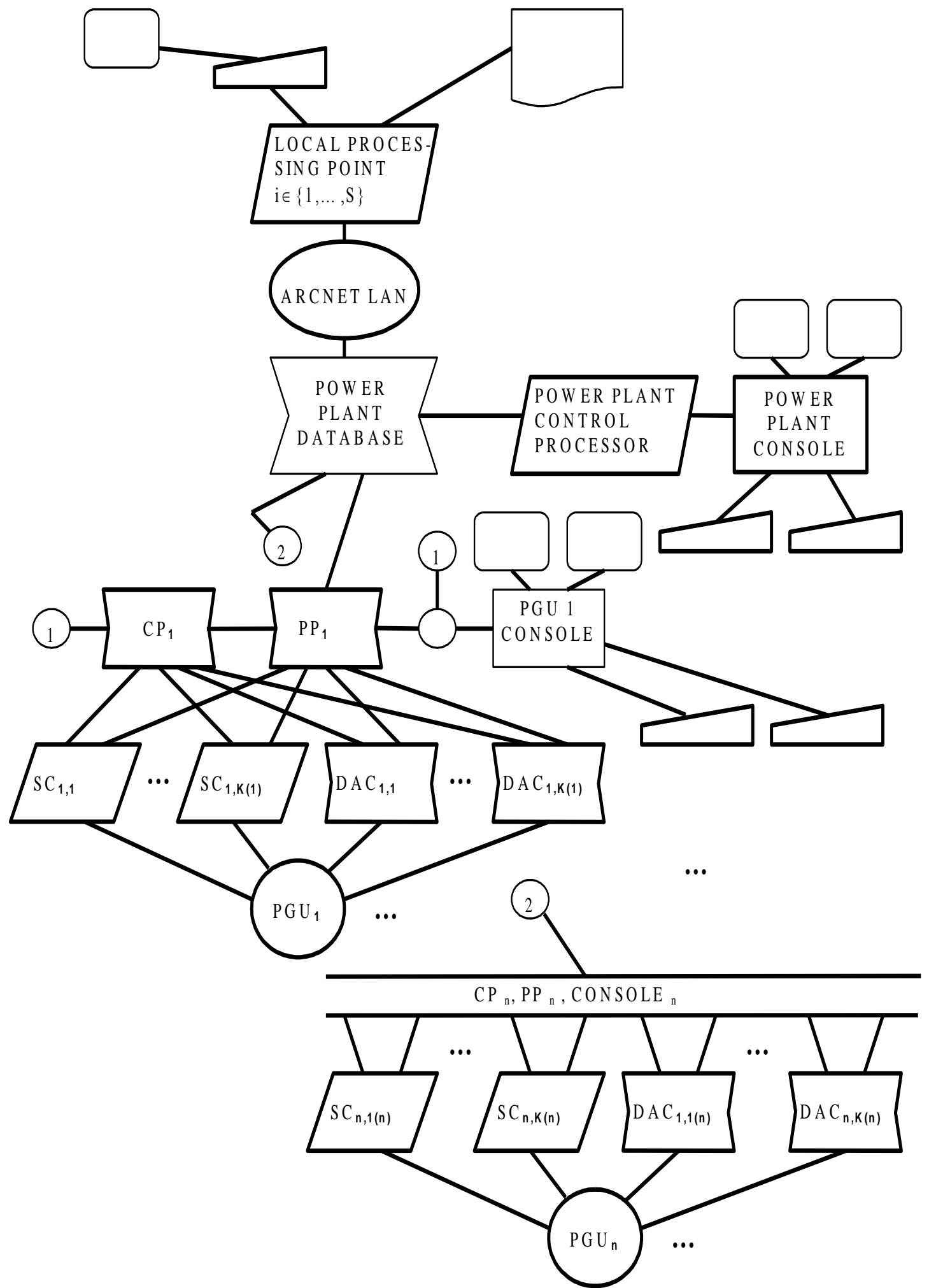

Figure 16 Hardware architecture of Badel 
In particular, the POWERSTER System developed by the functional transfer of the Badel solutions (especially $\mathrm{PP}_{\mathrm{i}}$, Ref. Fig, ). [11]. This system competed successful with big technology providers trying to get into the case study country market. In a high degree due to the due approach to effective trustiness problem solving, developed by the Team for the case study country.

\section{g) Final remarks}

The framework of the present paper is too narrow to mention all projects led by the Leader. There were a dozen or so important projects, executed successfully in the case study country. However, the exemplary systems portrayed shall enable to depict the basic thesis of the present paper that the trusted application, and operating software as well as system issues are to be cared about very diligently to gain successful systems, especially I the power industry and in the countries similar to the case study one. .

\section{DESIGN COSTS}

\section{a) Professional Fates of Leading Designers}

In the cases-study country, during the automation and ICT pioneering period, there prevailed the system known as WPR (Who has got Power is Right). That meant that the biggest benefits of any action in the country should be gained by the power called, ironically, the Power of People (PoP). This included also the important pioneering automation and ICT projects. When an important project was completed or even earlier, due to some PoP's mistake, PoP initiated some actions against the leading designer involved, oriented towards making impossible for her or him to continue its work as the important project leading designer. The actions were aimed towards providing all benefits of the project (money, fame of the pioneering creator, professional promotion, etc.) to PoP and not to the leading designer. The most kind action consisted in promoting the leading designer leading to that her or his ceased to be a leading designer at all and lost most of its strength. However, the much more frequent case was to dismiss the leading designer and prohibit, in practice, her or him to lead any more important projects.

Such behaviour prevailed in the automation and ICT domain in the case study country and, most probably, in other countries governed by WPR system,.

\section{b) The Costs Paid by the Leader}

To avoid the fate of all other leading designers of important ICT systems in the case study country, the Leader, from the very beginning of his professional carrier, chose a rather untypical approach to settle out his work on important projects. When the system designed was on the phase of commissioning, he changed the project, his team or even the employer and newer allowed to be involved in a dirty fight for money, promotion or the system creator's fame. Thus, he could be called a sucker of PoP.

But PoP loved suckers; even more, the basic task of each PoP was to make the whole society to become suckers, i.e. people who work and give all benefits of the work done to the PoPs. And they issued next orders to the Leader.

\section{c) Actual Costs Paid by the Leader}

The virtual costs borne by the Leader and mentioned hereinabove seem to be very high. However, the actual costs should be assessed by comparing those paid by other leading designers in the case study country.

The first thing here is that of money. All WPR systems were based on the severe underpayment rule (to make people obedient to various PoPs at a low price). So the leading designers had to do extra work to ensure some nice living level for their families. They could make money on the projects they led but their teams would not work hard enough and large-scale important systems would be infeasible. Other leading designers got their additional money from other automation and/or ICT projects. The Leader got it from translation what resulted in big benefits: maximum possible independence of WPR and PoPsw, extra money needed, information invaluable for the novel system Leader, much easier information exchange, etc. The Leader's design qualification would be much lower if he were not the translator and, on the contrary, his translation capabilities would be much lower if he were not the successful Leader. Even now when, due to the ill policy (Lewoc, 2010a) of the technology providers, no other leading designers occupy any significant technical position, the Leader may finance his ICT design and research work, and verify and proliferate his results on prestigious events. 
Referring the possible promotion, the Leader was always interested in keeping the position of an actual leading designer. Any promotion would be inappropriate since it could deprive him of his strongest point, a skillful leading designer capabilities.

Referring the fame of a creator; after some year or two, the PoPs involved signed his reference letters. Such reference letters were not issued for any other leading designers who terminated their projects fighting heavily with the relevant PoPs.

\section{CONCLUSION}

Thus it should be recognized that the Leader could not be thought about as a sucker of WPR and PoPs; on the contrary, in many professional aspects, WPR and various PoPs were his suckers.

This approach is very important for development of trusted applications, operating systems and functional systems, since years and years are needed for the Leading Designers and Teams to learn to adequate develop trustworthy solutions needed in countries similar to the case study onr.

\section{REFERENCES}

[1] M.-W. Han, J. B. Lewoc, A. I., S. Skowronski and A. Kieleczawa, Power Industry Computer Control System Design and Implementation Problems: A Case Study of Poland. IFAC (Eds.), Proceedings of the $17^{\text {th }}$ World Congress of IFAC, Seoul, IFAC, 2008, pp. 6703-6708.

[2] Jozef B. Lewoc, Antoni Izworski, Sławomir Skowronski, Antonina Kieleczawa, Georgi M. Dimirovski, Barriers to Ethical Behaviour: A Case Study of Poland. IFAC S. Bittani, A. Cenedese, S. Zampieri (Eds.), $18^{\text {th }}$ IFAC World Congress, Milan, Elsevier (Oxford, UK), 2011, p. 6.

[3] Elwro, Technical documentation of Odra 1300 computer family. Elwro, Wrocław, 1975 (In Polish).

[4] J. Lewoc, Simulation of a Computer Control System, Applicationes Mathematicae, XII, 3/1971/, p.10 .

[5] J. Sawicki, A. J. Kowalski, J. Lewoc, Implementation of the Automatic Data - Processing for the Power System Control in Poland, Data - Processing Conference, Nr 5.1.11, Madrid, 1974, 8p.

[6] J. B. Lewoc, M. Rozent, I. Saczuk, The computing power and the computer systems for the power industry in Poland, MICC (IFAC), Praha 1992.

[7] J. Lewoc et al., Primary data processing methods applied in power generating unit computer monitoring system, Power System Conference, Praga, 1978.

[8] J. Lewoc et al., Emulator of visual display units. 7180/2, Efektywnosc Zastosowan Minikomputerow w Gospodarce Narodowej, Zamek Ksiaz, 1978, p. 6 (in Polish).

[9] J. B. Lewoc, M. Rozent, E. Weksej, A power system simulator: Participation of people involved, IFAC (Eds.). Proceedings of ASBoHS, IFAC, Madison, 1992.

[10] J.. B. Lewoc, B. Lanowska, Hardware Structure of Power System Engineer Aid, Microcomputers and Their Applications. J. Malec (Ed.), Proceedings of the International School on Microcomputers and Their Applications, 1984, p. 6.

[11] J. B. Lewoc, E. Slusarska, A. Tomczyk, A distributed data base for real-time control / monitoring of power plants,. Rodd M. (ED.), Proceedings of Distributed Databases in Real - Time Control, IFAC/IFIP, Budapest, 1989, p. 6. 